\title{
BIOQ-BYWORD
}

\section{Shake Shack IPO Analysis}

\author{
Caixia Hu* \\ School of Accounting, Zibo Vocational Institute, Zibo 255300, China
}

*Corresponding author: Caixia Hu, kuku_hcx@ hotmail.com

\begin{abstract}
The restaurant industry is one of the largest and fastest growing sectors in the economy in the United States. According to the National Restaurant Association (NRA), the food service industry is the third largest industry accounting for more than 4\% of the country's gross domestic product (GDP). Shake Shack is an American fast food restaurant chain based in New York City. It started out as a food cart at Madison Square Park in 2000, and its popularity grew steadily. Shake Shack is currently one of the best fast-food restaurants in the world. This article discusses the successful business model of Shake Shack through IPO analysis.
\end{abstract}

Keywords: Shake Shack; IPO analysis; Business operation

Publication date: September 2021; Online publication: September 30, 2021

\section{Introduction}

By the time of Shake Shack's IPO on January 29th, 2015, the fast-food industry was already saturated with competition. People from different geographic areas had become devoted fans of their favorite burger places, some of which include In-N-Out, Whataburger, Five Guys, Red Robin, Culver's, Fuddruckers, and of course, Shake Shack. Any newcomers to this market would have to offer a truly unique product that stands out amongst all the competitors. This would be difficult because there are only so many things you can do to a burger. Shake Shack was able to venture into the market at an ideal time when they introduced their own sauce named ShackSauce. Just as McDonald's did with Big Mac Sauce and Chick-Fil-A with Chick-Fil-A Sauce, Shake Shack created something to ensure that their burgers stand out from the competition. The biggest challenge in entering this market is looking for customers and gaining market shares from competitors. As stated previously, many of these fast casual burger restaurants already had cult-like followers by 2015.

According to Statista, consumer spending at quick service restaurants increased by $3.02 \%$ in 2014 and $4.24 \%$ in 2015 . This leads people to believe that this industry was already in the expansion phase of the business cycle at the time of Shake Shack's IPO. Overall, it would have been extremely difficult for a new company to enter the market at this time. Even though the industry was still growing, the competition was strong and many of these other companies already had a strong foothold in their respective geographical regions within the United States ${ }^{[1]}$. A new company would have to offer something unique to really catch people's attention in order to succeed.

\section{Background}

The restaurant industry in the United States is one of the largest and fastest growing sectors in the economy. According to the National Restaurant Association (NRA), the food service industry is the third largest industry accounting for more than $4 \%$ of the country's GDP ${ }^{[2]}$. In 2015 , the restaurant industry reached $\$ 745.61$ billion, approximately $\$ 703$ billion increase from 1970. Since the United States is a multiethnic 
nation with a large population that is engaged in the restaurant industry, restaurants are an important driving force for economic development. According to the NRA statistics, there are over one million restaurants employing 15.6 million workers. The restaurant industry comprises of two categories: full-service restaurants (FSRs) and limited-service restaurants (LSRs). Full-service restaurants offer a full range of dining such Red Lobster, whereas limited-service restaurants are classified as fast-food chains. Well known fast food chains are McDonald's, Subway, Shake Shack, Taco Bell, Burger King, Chipotle, etc. These chain restaurants are everywhere, and they easily sell food at low prices. For example, hamburgers, fries, and sandwiches. Full-service restaurants generate more than $\$ 247$ billion in revenue through food and beverages while fast food chains generate more than $\$ 273$ billion revenue a year ${ }^{[3]}$.

Shake Shack is an American fast food restaurant chain based in New York City. It started out as a food cart at Madison Square Park in 2000, and its popularity grew steadily. It expanded its menu from New York-style hamburgers to fries, hotdogs, and its namesake milkshakes. Shake Shack is currently one of the best fast-food restaurants in the world. The company's expansion is happening so quickly that it can also be exponential. Shake Shack prides itself with using only $100 \%$ pure all-natural high-quality beef in their burgers, emphasizing that the meat used is completely free of hormones.

U.S. households' eating habits have changed tremendously. People have shifted from home-cooked meals to eating out at restaurants or having takeouts. According to the Bureau of Labor Statistics, the average American household spends \$3,459 on takeouts, dine-in restaurants, and on fast food meals. $90 \%$ of Americans prefer to dine-in at restaurants or order food, which has a lot to do with the convenience of eating out. Modern technology has made it possible, especially with the popularization of mobile phones and the interment, people can choose restaurants with various cuisines at any time, make reservations, or get food delivered to their doorsteps. According to American Customer Satisfaction Index (ACSI), more than 216 million U.S. consumers had visited a fast-food restaurant.

Home to the fast-food industry, the United States has more than 247,191 fast food establishments as of 2018 with more than 4 million people working ${ }^{[3]}$. The fast-food industry generated more than $\$ 273$ billion in 2019 alone ${ }^{[3]}$. The two dominant fast-food chains are Subway and McDonald's. According to Markets Insider, Subway accounts for $18.5 \%$ of all U.S. fast food restaurants, while McDonald's accounts for $11.3 \%$. However, McDonald's is the leading restaurant in terms of revenue with more than 36 million sales ${ }^{[4]}$. Shake Shack competitors include McDonald's, Wendy's, and Burger King.

\subsection{Demographic of the industry}

According to a study done by an economist, Jay Zagorksy, and an economics professor, Patricia Smith, the demographics of fast-food customers vary across income, age, and even ethnicity. Through a survey done from 2008 to 2012, they were able to find some discrepancy among fast food consumers across brackets divided into incomes less than $\$ 42,800$, incomes between 42,800 and 105,00, and incomes over 105,000. "So you see, both Democrats and Republicans, billionaires and poor people - pretty much everyone eats fast food," says Zagorsky.

However, it does not mean that there are no differences among fast food consumers and their consumption frequency. In their article, Zgaorsky and Smith did mention that there seems to be a positive relationship between how much someone works and how much they frequent fast food restaurants. Zagorsky mentioned that the reason for this essentially comes down to time. Those who work more may need quick bites, which can be provided by "fast" food, whereas those who work less may have more time to make their own meals.

The fact that their customer base can vary among differences, such as income and age, shows no lack of potential new customers as well as recurring customers. With fast food restaurants essentially at every corner or every major city across the globe, there is no lack of foot traffic. This coupled with the quick 
service for hardworking and busy people, the opportunity to grow and dominate is endless.

\subsection{History and development of Shake Shack}

Shake Shack first started in 2001 as a hot dog stand at Madison Square Park in Manhattan. The stand experienced great success its first three summers of operation, and in 2004, it moved to a permanent kiosk in the park. In its move to a permanent kiosk, Shake Shack expanded their menu to hot dogs, burgers, fries, and frozen custard. The restaurant was originally designed to be specific to New York without any plans to become a chain. In 2010, Shake Shack expanded their operations, opening restaurants throughout New York and a new location in South Beach Miami, Florida. In 2011, Shake Shack scored key locations in Grand Central Terminal, John F. Kennedy International Airport, and Citi Field. By 2015, Shake Shack had 63 locations all around the world.

A key component to Shake Shack's success is their business model. Since they had no intention to become a chain, they focused on creating a community gathering place ${ }^{[5]}$. Meyer contributes much of his success to how he started SS and what it meant to the New Yorkers.

Shake Shack's development is no doubt impressive as they went from a hot dog stand in 2001 to over 160 locations in 2020. At inception, it only had thoughts of being a New York exclusive restaurant but to now, where they are a global brand, is incredible. One special aspect about Shake Shack is its focus on providing locally sourced quality food and on creating a community gathering place, an aspect that had been implemented at its first location. Most of the competitors are focused on generating profit and do so by using lower quality food and services. Shake Shack's philosophy has been centered on creating enlightened hospitality for the employees, customers, and outside community as a whole; a philosophy that is evident in their current operations and certainly is an attribute to their success ${ }^{[6]}$.

\section{Consumers' inclination for Shake Shack}

Shake Shack sprung into the scene with a bold approach to the fast-food industry where they wanted an average burger joint to treat the customers as if they were dining at a fine dining establishment. Anyone who has visited a common fast-food restaurant in the States would know that McDonald's, Wendy's, or Taco Bell is designed for the complete opposite. The regular fast food joint focusses on volume; the focus is on acquiring the greatest number of customers through fast, cheap, and reliable service. Shake Shack aimed at bringing a higher level of fast-food experience to their customers. This helped Shake Shack present itself as a more polished product, one where the customers would attach a higher brand quality along with its name. Fundamentally, when an establishment aims at bringing a higher quality customer service, this means that they would need to invest more into their brand image and presentation. Naturally, this would raise the price of the product relative to the cheap and fast approach of the high-volume fast-food neighbors. This business model, therefore, is aimed at the upper-middle class rather than the everyday American, who can zoom through a Burger King drive-thru for a burger in half the time and half the price. The higher price that goes into Shake Shack's higher quality presentation leads the average middle-class American to weigh that price difference and therefore, choose to spend that extra money for the quality premium. This leaves the average Shake Shack customer to be of a more affluent background. This is also the reason as to why the founder, Daniel Meyer, chose certain locations where he knew the crowd would better fit his restaurant's vision. This was all to say that Shake Shack was never really aimed to take down the industry leaders when it stepped into the fast-food industry. Rather, Shake Shack was the leader in a new range of food service that is better differentiated from traditional fast food as an entirely new market. Shake Shack was the industry leader in the creation of the premium fast-food market. This market realizes that it is delivering a better product than that of the fast-food market, but it still brands itself as such to reach out and gain the 
sales that those companies have gained by presenting themselves as an accessible business.

Shake Shack was seen as a refreshing reinvention of the burger experience when it opened up in New York City. Customers were lining up, at times, for hours just to have a meal at the stand located in Madison Square Park. Within the span of two decades, the business rapidly expanded from one location to over two hundred across the world. Clearly, this explosive growth was driven by the high demand the customers had for the product. Wherever Shake Shack expanded, customers appeared as well. The investment market also shared in the excitement when the stock first went public.

On its' opening day, the price of their stock went up from $\$ 21$ to $\$ 47$. Since then, the stock went all the way up past $\$ 100$ per share for a brief moment in the years after. This shows that the market is appreciating the company's growth in value and worth. However, it remains to be seen how the COVID-19 pandemic and ensuing recession impact the company and its price per share. The market has already seen the price of the share coming down from September 2019. Further complications due to the slowing down of demand can affect the price even further if the economy does not bounce back soon.

\section{Shake Shack's IPO and its business operation}

Shake Shack's operation model has allowed it to differentiate itself from many other popular restaurants in the United States. It attempts to connect its high-quality driven food and pair it with a one-of-a-kind dining experience. Finally, these two key factors are brought together by Shake Shacks' strategic location selection. As stated to investors by Shake Shack's management, "We believe that the culture of our team is the single most important factor in our success. We aim to recruit and develop a team with the innate 'personality to please' that cannot be taught." This enforces the idea that Shake Shack takes large pride in its staffs' ability to create a one-of-a-kind experience for its customers. The company attempts to achieve this by providing extensive leadership programs for its management. It also ensures that working for Shake Shack is rewarding at all levels by offering higher than average compensation to its employees. In the District of Columbia area, Shake Shack locations were paying $\$ 12$ per hour as opposed to the $\$ 10.50$ minimum wage in addition to providing benefit programs and opportunities for employees to become leaders within the organization. All this is in hopes to create an enjoyable dining experience for the customers.

Shake Shack offers its customers high quality meal to be enjoyed in their establishments. "We embrace our company's fine-dining heritage and are committed to sourcing premium, sustainable ingredients, such as all-natural, hormone and antibiotic-free beef, while offering excellent value to our guests." These highquality ingredients become crucial in fulfilling the demand of more health-conscious food. The firm continues to become innovative and add new items to its menu.

\subsection{Supply chain}

Shake Shack's mission is to create quality food and a quality experience for its consumers. In order to do so, they needed to establish a well-organized and strong supply chain. Their required supplies for operations are almost no different from any other restaurants in the U.S. However, what made them different is how their supplies are maintained and their ability to build strong relationships with their suppliers. As stated in an article by FastCasual, "Initially, and around the time of its IPO, Shake Shack's beef production was focused in New York City, but the chain has been adding butchers across the country as it expands its footprint. It also has a limited number of suppliers for its other major ingredients, including beef patties, chicken, potato buns, custard, Portobello mushrooms, and cheese sauce," expanding the number of suppliers allowed Shake Shack to build stronger relationships with communities and also decrease the power of their suppliers as they further expanded where their materials came from. 


\subsection{Locations and customer demographics}

Shake Shack had 63 locations at the time they conducted their IPO, of which 31 were domestic company operated, 5 were domestic licensed, and 27 were international licensed. Their location strategy was to open new chains where communities gathered with high foot traffic and substantial commercial density along with other traffic drivers, such as areas close to parks, museums, schools, hospitals, and tourist attractions. Several examples are New York's Theatre District, London's Covent Garden, and Dubai's Mall of the Emirates. Shake Shack have also launched different layouts and sizes of each Shack in different locations to connect directly to the neighborhood. Shake Shack has continued to expand in the U.S. and internationally with having more than 275 locations as of $2020^{[7]}$. Their locations fit with their business strategy of having Shacks in neighborhoods that have high foot traffic in busy cities and suburbs.

\subsection{Initial public offering}

With a total of 11,308,147 common shares (A) offered, of those, 5,000,000 shares offered by Shake Shack and an additional 6,308,147 issued for former SSE Equity Owners and UAR Plan Participants, that along with 24,191,853 Class B common stocks, all of which would be owned by Continuing SSE Equity Owners. The IPO plan in the short term and near future keeps the investors optimistic as they continue to plan to open at least 10 Shacks per year domestically and look to expand internationally, creating a global brand in the marketplace. They also came up with possible contingency plans as they understand the uncertainty of their future growth due to the inability to obtain locations, global economy, food discrepancies, or other external factors. The net proceeds would be used for repaying outstanding borrowings. This in turn can help with its liquidity and debt to equity value, thus increasing its value.

On the grant date, the fair value seemed to have been calculated at $\$ 21.00$ based upon the Black-Scholes valuation model that takes into consideration of its expected volatility, dividend yield (none), term in years, and risk-free interest rate. The price at the time, compared to today, was a very well based price. A huge obstacle this stock had to go through is that the overall net income and the net income per stock showed a decreased after one fiscal year. Shack sales had shown to have gone up, but it also seems that their costs increased with declining growth from Shack-to-Shack locations.

\subsection{Overvalued or undervalued?}

It is believed that Shake Shack's IPO was fairly valued at the time of the IPO as this company has high aspirations to grow domestically and internationally, showing past profitability and aspirations for the future. One of the bigger negatives going against Shake Shack is the fact that Shake Shack continues to have growing costs and past borrowings that need to be paid off. As compared today and to other competitors, it is believed that it is overvalued as its $\mathrm{P} / \mathrm{E}$ ratio far exceeds its competitors and the industry average due to the accumulated expenses and debts since their IPO.

\section{Conclusion}

During these dire and risky times, the market price for Shake Shack in the short term can be expected to fall as it did in mid-February and may continue to do so as stay-at-home orders continue to be in effect and the hope for the effects of the virus continue to be combatted. Much of the industry, especially those in the fast-food industry, are still working to fill orders for home delivery, but obviously with reduced overall sales, it may affect earnings and debts due by the company. Since being liquid is very important during this time, it may be difficult for Shake Shack to handle such debts as its liquidity is low. In long-term, theoretically, it would help Shake Shack to grow as more and more states begin to reopen for business and public policies such as stay-at-home orders will start to loosen. The only problem with such a theory is 
exactly that, it is just a theory. During these times, there is no guarantee what may or may not happen as the events of COVID-19 is one of the first events to occur on a global scale. The best-case scenario is that when the operations are scaling back up to prior numbers, the share price would rise, but it would not be as high as its past 52-week high. In the end, there is no surefire result for Shake Shack in the future especially in regard to its share price, but one must hope for the best in these situations.

\section{Disclosure statement}

The author declares that there is no conflict of interest.

\section{References}

[1] Jaaskelainen L, Topic: Restaurant Industry in the U.S., Statista. www.statista.com/topics/1135/usrestaurants/ (accessed on May 2020).

[2] National Statistics, National Restaurant Association. restaurant.org/research/restaurantstatistics/restaurant-industry-facts-at-a-glance (accessed on May 2020)

[3] Lock S, 2019, Fast Food Industry Market Share Worldwide, by Brand 2019, Statista. www.statista.com/statistics/273057/value-of-the-most-valuable-fast-food-brands-worldwide/ (updated August 16, 2019).

[4] Tyler J, 2018, These Are the Biggest Fast-Food Chains in America, Markets Insider. markets.businessinsider.com/news/stocks/biggest-fast-food-chains-in-america-2018-61027311443\#19-five-guys2 (updated June 22, 2018).

[5] Hayes A, 2020, The Story Behind Shake Shack's Success, Investopedia. www.investopedia.com/articles/personal-finance/041615/story-behind-shake-shacks-success.asp (updated March 25, 2020).

[6] ShakeShack, Inc. Competitors, Nasdaq. www.old.nasdaq.com/symbol/shak/competitors?page=

[7] Shake Shack, Inc. (SHAK), Stock Price, Quote, History \& News, Yahoo! Finance. finance.yahoo.com/quote/SHAK/ (updated April 30, 2020). 